\title{
Mid-upper arm circumference in pregnant women and birth weight in newborns as substitute for skinfold thickness: findings from the MAASTHI cohort study, India
}

Giridhara R. Babu ${ }^{1,2^{*}}$, Aritra Das ${ }^{3}$, Eunice Lobo ${ }^{1}$, Deepa R${ }^{1}$, Daisy A. John ${ }^{1}$, Prashanth Thankachan ${ }^{4}$, Sonalini Khetrapal ${ }^{5}$, Sara E. Benjamin-Neelon ${ }^{6}$ and GVS Murthy ${ }^{7,8}$

\begin{abstract}
Background: Estimating total body fat in public hospitals using gold-standard measurements such as air displacement plethysmography (ADP), deuterium oxide dilution, or dual-energy X-ray absorptiometry (DXA) is unaffordable, and it is challenging to use skinfold thickness. We aimed to identify the appropriate substitute marker for skinfold thickness to estimate total body fat in pregnant women and infants.

Methods: The study is part of a prospective cohort study titled MAASTHI in Bengaluru, from 2016 to 19. Anthropometric measurements such as body weight, head circumference, mid-upper arm circumference (MUAC), and skinfold thickness were measured in pregnant women between 14 and 36 weeks of gestational age; while measurements such as birth weight, head, chest, waist, hip, mid-upper arm circumference, and skinfold thickness were recorded for newborns. We calculated Kappa statistics to assess agreement between these anthropometric markers with skinfold thickness.

Results: We found the highest amount of agreement between total skinfold thickness and MUAC (Kappa statistic, $0.42 ; 95 \% \mathrm{Cl} 0.38-0.46)$ in pregnant women. For newborns, the highest agreement with total skinfold thickness was with birth weight $(0.57 ; 95 \% \mathrm{Cl}$ 0.52-0.60). Our results indicate that MUAC higher than $29.2 \mathrm{~cm}$ can serve as a suitable alternative to total skinfolds-based assessments for obesity screening in pregnancy in public facilities. Similarly, a birth weight cut-off of $3.45 \mathrm{~kg}$ can be considered for classifying obesity among newborns.

Conclusion: Mid-upper arm circumference and birth weight can be used as markers of skinfold thickness, reflecting total body fat in pregnant women and the infant, respectively. These two anthropometric measurements could substitute for skinfold thickness in low- and middle-income urban India settings.
\end{abstract}

Keywords: anthropometric markers, India, Karnataka, skinfold thickness

\footnotetext{
* Correspondence: epigiridhar@gmail.com

'Indian Institute of Public Health-Bengaluru, Public Health Foundation of India (PHFI), Bengaluru, India

${ }^{2}$ Wellcome Trust-DBT India Alliance Intermediate Research Fellow in Public Health, Hyderabad, India

Full list of author information is available at the end of the article
}

(c) The Author(s). 2021 Open Access This article is licensed under a Creative Commons Attribution 4.0 International License, which permits use, sharing, adaptation, distribution and reproduction in any medium or format, as long as you give appropriate credit to the original author(s) and the source, provide a link to the Creative Commons licence, and indicate if changes were made. The images or other third party material in this article are included in the article's Creative Commons licence, unless indicated otherwise in a credit line to the material. If material is not included in the article's Creative Commons licence and your intended use is not permitted by statutory regulation or exceeds the permitted use, you will need to obtain permission directly from the copyright holder. To view a copy of this licence, visit http://creativecommons.org/licenses/by/4.0/. The Creative Commons Public Domain Dedication waiver (http://creativecommons.org/publicdomain/zero/1.0/) applies to the data made available in this article, unless otherwise stated in a credit line to the data. 


\section{Introduction}

The increasing prevalence of overweight and obesity among children is a significant public health issue attributing to immediate and long-term health problems [1]. However, the available estimates of obesity are highly variable in India, suggesting a range of 1 to $29 \%$ of children [2-5] and $11.1 \%$ in pregnant women [6]. There is an intergenerational cycle of perpetuating association of obesity in mothers with that of children, leading to a myriad of diseases such as type 2 diabetes mellitus (T2DM), dyslipidemia, and cardiovascular disease (CVD). Obesity has increased in adults and children owing to the epidemiological, demographical, and nutritional transition in India. From 1990 to 2017, the prevalence of children with obesity has increased annually by $4.98 \%$, with a projected prevalence of $17.5 \%$ by 2030 [7]. In order to start effective strategies to reduce adverse outcomes, it is necessary to evaluate pregnant women and children for obesity using reliable markers that can be scaled across the nation.

Maternal obesity rates are disproportionately higher in Low-Middle income countries (LMICs) as India and can have adverse health outcomes for mothers and children. In India, Chopra et al. analyzed the National Family and Health Survey-4 (NFHS-4) data and reported obesity among $12 \%$ of pregnant women 20 years and above, with as high as above $40 \%$ high in over 30 districts in multiple states [8]. Similarly, in children of South Asia, the overall prevalence of overweight and obese children was reported as 1.91 and $0.89 \%$, respectively [9]. Further, the NFHS-5 survey also found a rise in obesity among children under five years of age in 20 of the 22 states where the study was conducted [10]. A study in rural Haryana also reported the prevalence of macrosomia among live births as $1.3 \%(n=12)$ [11].

Lack of clear recommendations adds to the complexities of screening during pregnancy and infancy. First, there is no standard definition of what constitutes obesity in pregnancy and at birth. The available recommendations are mostly for pre-pregnancy measures [12]. Second, there are ambiguities in the methods for screening obesity, with some using birth weight while others suggesting BMI z-scores or weight-for-length (WFL). The reliability of anthropometric markers in estimating obesity is a substantial challenge. For example, poor sensitivity $(47.7 \%)$ and positive predictive value $(67.7 \%)$ are noted for BMI [13]. Studies across different settings have shown that high MUAC has high diagnostic accuracy (sensitivity, specificity, and predictive values) for the identification of adiposity (as measured by body composition techniques [14]. Fourth, it is difficult to ensure that trained staff is available to maintain homogeneity and internal validity [13]. Finally, when measured using standard methods, there are high chances of measurement error, often depending on the number of observers, skill and staff turnover [15].

There are several advanced methods with higher reliability for measuring obesity. These include bioelectrical impedance analysis (BIA), deuterium dilution, dualenergy $\mathrm{x}$-ray absorptiometry (DXA), hydrostatic weighing, ultrasound, and magnetic resonance imaging (MRI). Unfortunately, using these instruments is either costly, challenging to implement at the population level, and also requires considerable expertise [16, 17]. Due to these complexities in measuring the total body fat, measuring the thickness of two layers of subcutaneous fat pinched using calipers referred to as total skinfold thickness is generally employed in community settings [18].

It is essential to screen obesity in public facilities using appropriate but realistic methods to assess total body fat in the body. Hence, using total skinfolds for assessing body composition is a quick, convenient, relatively inexpensive method across all ages. However, this requires rigorous training and expertise. In addition to the possibility of high Intra- and inter-observer variability in using the calipers [19], multiple readings in at least three sites are necessary to obtain reliable skinfold thickness. This will not be possible in most public facilities, which are otherwise understaffed, overcrowded, and offer no privacy. It is difficult to ensure frontline health workers have the necessary training and reduce intra- and interobserver variability in millions of health workers. Therefore, we aimed to assess the validity and determine appropriate cut-off levels of several anthropometric markers as alternatives for total skinfolds in pregnant women and newborn infants in a prospective cohort study.

\section{Methods}

\section{Study design and subjects}

Maternal Antecedents of Adiposity Studying the Transgenerational role of Hyperglycemia and Insulin (MAAS THI) is a prospective pregnancy cohort. A detailed protocol and methods are published elsewhere [20]. In brief, we recruited voluntarily consenting eligible pregnant women from public facilities in Bengaluru, Karnataka, from 2016 to 2019. We excluded participants with Diabetes, Human immunodeficiency virus (HIV), and Hepatitis or their inability to complete the oral glucose tolerance test (OGTT). The included women were aged 18-45 years, having singleton pregnancy before the gestational age of 36 weeks. This was done with the clinical information and reference standards that were available to the performers of the index test and the reference test. We collected the data and measured anthropometry from the voluntarily consenting pregnant women between 14 and 36 weeks. Women were invited for laboratory tests (glucose and haemoglobin) between 24 and 36 
weeks. Follow-up was conducted in the women who completed the lab tests, and we considered infants from birth to five months of age.

\section{Anthropometric measurements Pregnancy}

Standing height and weight were measured using the portable stadiometer (SECA 213) and digital weighing scale (Tanita). We recorded weight to the nearest 100 gram with minimal clothing and barefoot. The height was read to the nearest $0.1 \mathrm{~cm}$. Mid-upper arm circumference (MUAC) was measured for the left arm using circumference tape (Chasmors WM02). The women were asked to sit/stand with their back to the measurer, and the elbow flexed at about 90 degrees. The tip of the acromion (the point of the shoulder) and the olecranon processes were palpated and marked with a skin pencil. The distance between these two points was measured by a flexible measuring tape, and a point midway between these two processes was marked on the skin. This midpoint marked the vertical level at which the circumference was measured with the arm hanging by the side. The measuring tape was placed around the upper arm such that the tape was horizontal to the surface. It was ensured that the tape rested firmly against the skin but not pulled too tight to cause indentation of the skin surface [21]. Two readings for each anthropometric measurement were recorded. Head Circumference (HeadC) was measured using Chasmors WM02.

\section{Newborn anthropometry}

For weight measurement, newborns were placed naked on the digital weighing scale (SECA 354), and two readings to the nearest $0.5 \mathrm{~g}$ were taken. The newborn length was measured using Infantometer (SECA 417).

\section{Total skinfold thickness}

We measured triceps, biceps, and subscapular skinfold thickness in pregnant women between 14 and 36 weeks of pregnancy. For newborns, measurements were done between birth and five months of age. The measurement was conducted on the left side using Holtain Calliper (Holtain, U.K 610ND). Triceps skinfolds were measured over the posterior belly of the triceps muscle of the left arm, halfway between the acromion and the olecranon, on a line passing upwards from the olecranon in the axis of the limb, with the arm extended. Biceps skinfold is measured in the anterior midline of the arm over the biceps on the same level as the triceps skinfold. Subscapular skinfold was measured immediately below the angle of the left scapula, with the arm held by the side of the body. Measurements were made on the left side of the body, and readings were taken $5 \mathrm{~s}$ after applying the caliper's jaws. Three readings to the nearest $0.2 \mathrm{~mm}$ were taken.

\section{Quality control and calibration}

All research assistants were trained at the St. Johns Research Institute, Bengaluru, for anthropometric measurements as part of their induction. Competencies of research assistants were assessed at the outset, followed by mandatory annual certification. The relative intraobserver technical error of measurement was below $1.5 \%$ for all measurements and the relative interobserver technical error of measurement (TEM) was below $2 \%$. Calibration of all the equipment was done every month.

\section{Statistical analysis}

Descriptive statistics, mean and stratum-wise proportions (as applicable) were generated for sociodemographic and anthropometric characteristics of the study participants. For the anthropometric measures for which multiple readings were available, the arithmetic mean of the non-missing values was used in the analysis. Total skinfold thickness was calculated by summing up the values for biceps, triceps, and subscapular skinfold thicknesses. Curve estimation was done to assess the linearity of the association between total skinfold and other explanatory anthropometric measures (Transreg procedure in SAS that utilized the Box-Cox transformation of the dependent variable). The strength of linear association (and statistical significance) was described using simple linear regression. After establishing a linear association between total skinfold and the rest of the anthropometric parameters, Pearson's correlation analysis between these parameters was assessed. Percentile distribution of maternal skinfold thickness was derived, and based on 90th percentile cut-off, the participating pregnant women were categorized into high (above 90th percentile and normal skinfold (up to 90th percentile) groups.

For the newborns, the 85th percentile cut-off was used [22]. Receiver operating characteristics (ROC) curve analysis was performed, and separate ROC curves of maternal body weight, head circumference, MUAC, and body mass index (BMI) on 90th percentile cut-off of total skinfold were generated. The optimal cut-off point for each of these measures that corresponded to 90th percentile total skinfold cut-off was determined using the following three methods - (1) Youden's J statistic; (2) minimized distance to $(0,1)$ point in the ROC curve; and (3) sensitivity-specificity equality [23-27]. In case conflicting cut-off values were obtained from each of the three methods, the results generated by Youden's $J$ statistic procedure were persisted with. For the newborns, the same process was repeated to determine the optimal 
cut-off of different anthropometric measures corresponding to the 85th percentile cut-off for total skinfolds. Besides the anthropometric parameters used for pregnant women, chest (CC), waist (WC), and hip circumferences $(\mathrm{HC})$ were additional parameters evaluated for newborns. Further, the predictive accuracy of the cut-off points for different anthropometric parameters was evaluated by calculating the proportion of misclassification that would result from the use of determined cut-offs. We also assessed Cohen's Kappa statistic to determine the agreement between the determined cut-off and standard 90th /85th percentile cut-offs for total skinfolds. SAS version 9.4 was used for statistical analyses.

\section{Results}

The research team approached 5725 pregnant women, 913 were ineligible A total of 4812 respondents were recruited, (Supplementary Fig. 1) anthropometry was recorded in 3719 pregnant women, and as seen in Table 1: the mean age was 24.2 years. Majority of them had attained middle school education (91.2\%), $22.7 \%$ had parents with diabetes, $45.1 \%$ of them were primiparous, and one in nine $(11.1 \%)$ women were diagnosed with Gestational Diabetes Mellitus (GDM) during the current pregnancy. Of the 3719 pregnant women, 2962 completed the lab tests, women who did not complete the lab tests were not followed up as per the study protocol. Among 2962 pregnant women, there were 60 cases of child death, 290 women had not delivered as of the analysis date, and there were 180 cases lost to follow up as they were not available on phone or at the given address. Infant anthropometry was measured in 2432 infants. The median birth weight was 2.9(0.74), and the interquartile range (IQR) was $0.73(2.6,3.33) \mathrm{kg}$, and the total skinfold thickness was $\mathrm{mm}$. The median gestational age at delivery was 12.16 weeks and the interquartile range is 2.27. The characteristics of the study population are summarized in Table 1.

The optimum cut-off values for the various anthropometric measurements corresponding to the 90th percentile cut-off of the total maternal skinfold thickness are shown in Table 2. Although the cut-off values obtained via different ROC curve methods were not identical, they approximated each other. Given the discordance, the cut-offs generated using Youden's $J$ statistic method $-66.89 \mathrm{~kg}$ for weight, $53.39 \mathrm{~cm}$ for HeadC, $29.20 \mathrm{~cm}$ while considering MUAC, and $27.82 \mathrm{~kg} / \mathrm{m}^{2}$ for BMI - were selected as optimal.

Table 3 depicts the resultant distribution of the 90th percentile of total skinfold according to the optimal cutoff values for the four maternal anthropometric measures, derived from the ROC curve analyses. MUAC cut- off had the least amount of misclassification (15\%), while HeadC cut-off had the highest (worst) misclassification (32.46\%). The highest amount of agreement (as per Kappa statistic) with total skinfold was also attributed to MUAC cut-off value (0.42 (95\% CI 0.38-0.46)). The area under the curve was the largest for the BMI cut-off (86.9\%), however, MUAC cut-off was quite close at $85.2 \%$ (Fig. 1). Therefore, considering all aspects, MUAC cut-off emerged as the best possible substitute for measuring total skinfolds in pregnant women. All four anthropometric measures demonstrated statistically significant Pearson's correlation and slope of linear association with the total skinfold thickness (Supplementary Fig. 2).

The optimum cut-off values for the various anthropometric measurements corresponding to the 85th percentile cut-off of the total skinfold thickness of the newborns are shown in Table 4. Similar to the mothers, the cut-off values for each of the seven anthropometric measures for the newborns were not identical but they approximated each other. The Youden's $J$ statistic method revealed the following cut-off values $-3.45 \mathrm{~kg}$ for body weight, $35 \mathrm{~cm}$ for HeadC, $33.7 \mathrm{~cm}$ for CC, $31.7 \mathrm{~cm}$ for $\mathrm{WC}, 30.3 \mathrm{~cm}$ for $\mathrm{HC}, 10.30 \mathrm{~cm}$ for MUAC and $13.22\left(\mathrm{~kg} / \mathrm{m}^{2}\right)$ for BMI (Table 4). The Pearson's correlation and the strength of linear association between the seven anthropometric measures and the total skinfold thickness of the newborns are presented in Supplementary Fig. 3. Each of the seven anthropometric parameters in the newborns showed a statistically significant positive Pearson's correlation with the total skinfold thickness and had a significantly upward slope in linear regression. On ROC curve analysis, the birth weight of the newborn had the highest area under the curve (89.8\%) among all seven anthropometric measures (Fig. 2).

We found that the birth weight cut-off was a good substitute for the total skinfold thickness of the newborns as it demonstrated the lowest amount of misclassification among all seven anthropometric measures (Table 5). The birth weight cut-off also had the highest Kappa statistic (0.57) demonstrating a better agreement with 85th percentile of the total skinfold thickness compared to the rest of the anthropometric measures.

The extent of misclassification that would result from the use of the newly defined cut-offs instead of the accepted standard, i.e. 85th percentile of total skinfold in newborns, along with the amount of agreement (expressed by Kappa statistic) between each of the seven measures and total skinfolds cut-off. Our results indicate that the birth weight cut-off $(3.45 \mathrm{~kg})$ had the least amount of misclassification (13.00\%) against the 85th percentile of the total skinfold thickness, while the BMI cut-off had the highest (worst) misclassification (24.11\%). The highest value of Kappa statistic was also 
Table 1 Demographic characteristics of participants $(N=3719)$

Maternal characteristics $(n=3720)$

Maternal age in years (Mean \pm SD)

$24.26 \pm 4.08$

Gestational age at recruitment in weeks (Mean \pm SD)

$23.5 \pm 6.01$

\section{Education}

Primary School and below

Middle School and above

\section{Gravida}

Primigravida

1467(39.40\%)

Multigravida

Parity

Nulliparous

$1667(44.80 \%)$

Primiparous

$1677(45.10 \%)$

Multiparous

$375(10.10 \%)$

Current gestational diabetes status during the assessment

Yes

$417(11.10 \%)$

No

Anthropometry measurements

Weight $(\mathrm{kg})$ (Mean \pm SD)

$58.95 \pm 11.72$

Height $(\mathrm{cm})($ Mean \pm SD)

$153.9 \pm 5.72$

Mid-upper arm circumference(cm) (Mean \pm SD)

$26.0 \pm 3.87$

Biceps skinfold thickness $(\mathrm{mm})$ (Mean \pm SD)

$10.63 \pm 4.90$

Triceps skinfold thickness $(\mathrm{mm})$ (Mean \pm SD)

$19.56 \pm 5.98$

Subscapular skinfold thickness $(\mathrm{mm})$ (Mean $\pm \mathrm{SD}$ )

$17.26 \pm 6.00$

Sum of skinfold thickness (mm) (Mean \pm SD)

$47.45 \pm 14.8$

Delivery outcomes ( $n=2432)$

Gestational age at delivery in weeks (Mean \pm SD)

$38.6 \pm 1.6$

\section{Delivery type}

Vaginal delivery

Caesarean delivery

Infant characteristics ( $n=2432)$

\section{Sex}

Male

Female

Age at assessment in days (Mean \pm SD)

\section{Anthropometry measurements}

Weight $(\mathrm{kg})($ Mean $\pm \mathrm{SD})$

$3.07 \pm 0.736$

Length $(\mathrm{cm})$ (Mean $\pm \mathrm{SD})$

$49.55 \pm 3.88$

Crown-rump length $(\mathrm{cm})$ (Mean $\pm \mathrm{SD}$ )

$32.59 \pm 3.21$

Head circumference $(\mathrm{cm})$ (Mean $\pm \mathrm{SD}$ )

$33.76 \pm 2.16$

Chest circumference $(\mathrm{cm})$ (Mean $\pm \mathrm{SD}$ )

$32.33 \pm 2.81$

Waist circumference $(\mathrm{cm})$ (Mean $\pm \mathrm{SD})$

$30.75 \pm 3.72$

Hip circumference $(\mathrm{cm})($ Mean \pm SD)

$29.16 \pm 3.72$

Mid-upper arm circumference $(\mathrm{cm})$ (Mean \pm SD)

$9.89 \pm 1.22$

Biceps skinfold thickness $(\mathrm{mm})$ (Mean $\pm \mathrm{SD}$ ) 
Table 1 Demographic characteristics of participants $(N=3719)$ (Continued)

\begin{tabular}{lc}
\hline Characteristics & $\mathbf{n ( \% )}$ \\
\hline Triceps skinfold thickness (mm) (Mean $\pm \mathrm{SD})$ & $5.19 \pm 1.48$ \\
Subscapular skinfold thickness (mm) (Mean $\pm \mathrm{SD})$ & $4.97 \pm 1.38$ \\
Sum of skinfold thickness (mm) (Mean $\pm \mathrm{SD})$ & $14.20 \pm 3.69$ \\
\hline $\begin{array}{l}\text { SD, standard deviation; }{ }^{*} \text { Others: Christian and Jain; \#Occupation: Unskilled: labourer, construction labourer, helper, attender; Peon, cleaner, sweeper, Semi-Skilled: } \\
\text { Gatekeeper/Security, Asst. Operator, Asst. electrician, waiter, Skilled: Tailor, carpenter, Driver, plumber, electrician }\end{array}$
\end{tabular}

attributed to Birth weight $(0.57$ (0.52-0.60)] followed by the head and chest circumferences, respectively. The cut-offs for circumferences at the waist, hip, and mid-upper arm and BMI showed fair agreement with total skinfold thickness. Therefore, on the basis of the extent of misclassification and agreement, the birth weight cut-off emerged as the best substitute (among all anthropometric measures).

\section{Discussion}

There is a need to use feasible and accurate nutritional status indicators in pregnant women and newborn children to identify adiposity, an independent cardiometabolic risk factor. The burgeoning epidemic of obesity impacts all age groups and negatively impacts the life course and generations. Our results indicate that MUAC higher than $29.2 \mathrm{~cm}$ can serve as a suitable alternative to total skinfolds-based assessments for obesity screening in pregnancy in resource-constrained public health facilities. Similarly, a birth weight cut-off of $3.45 \mathrm{~kg}$ can be considered for classifying obesity among newborns.

Pre-pregnancy measurements are rarely available in most Indian setting [28]. As per the national survey [29], $59 \%$ rural and $41 \%$ of urban pregnant women avail public facilities for antenatal care, they mostly have their first antenatal visit late in the first trimester (or even later), making the bodyweight an unreliable indicator for assessment of overweight or obesity in pregnancy [30]. Since body weight is also integral to BMI estimation, this also suffers from the same limitation as a marker for obesity. Therefore, to obtain a reliable marker for obesity at any given point during the gestational period, we attempted to use MUAC measurements. Our results showed concordance with the studies from Sri Lanka and Nigeria, wherein the reliability of inexpensive MUAC is validated [31, 32]. Measuring MUAC in pregnancy eliminates the need for sophisticated equipment and calculations and is a reliable proxy of pre-pregnancy body fat and nutrition. These reasons also make MUAC a popular and feasible choice in public facilities [33-35]. A recent study conducted among adolescents, lactating, and parous non-pregnant women in one of the most impoverished regions in India reported that MUAC could be a viable marker for assessing women's nutritional status in community settings [27]. Maternity care guidelines in South Africa, a country with a similar economic profile and maternal health challenges as India, recommend using MUAC greater than $33 \mathrm{~cm}$ to indicate obesity in pregnant women [34]. The evidence from Argentina suggests MUAC cut-off points according to the gestational age [35].

Birth weight is a reliable predictor of body composition in newborns, explaining up to $84 \%$ of body fat in newborns $[36,37]$. Previous studies have shown that Indian babies preserve more subscapular skinfold thickness at birth even though these children had a lower birth weight [38]. However, this was not replicated in recent studies that showed that Skinfold thicknesses in Indian babies were similar to those reported in a Western population with comparable birth weights. Some of these studies used more accurate measurements of body composition like deuterium dilution and air displacement plethysmograph $[37,39,40]$. Studies have shown a significant positive correlation between body weight and body fate percentage across the weight range of $2.3-4 \mathrm{~kg}$

Table 2 Cut-offs for different anthropometric measures corresponding to total skinfold thickness cut-off (90th percentile) in pregnant women, by different methods of ROC curve analysis. [ $N=3719]$

\begin{tabular}{|c|c|c|c|}
\hline \multirow[t]{2}{*}{ Anthropometric measure } & \multicolumn{3}{|c|}{ Cut-off corresponding to 90th percentile of total skinfold thickness from different methods } \\
\hline & $\begin{array}{l}\text { Youden's } J \\
\text { statistic** }\end{array}$ & $\begin{array}{l}\text { Minimized distance to }(0,1) \text { point in the ROC } \\
\text { curve }\end{array}$ & $\begin{array}{l}\text { Sensitivity-specificity } \\
\text { equality }\end{array}$ \\
\hline Bodyweight (kg) & 66.89 & 66.89 & 64.94 \\
\hline Head circumference $(\mathrm{cm})$ & 53.39 & 53.39 & 53.09 \\
\hline $\begin{array}{l}\text { Mid-upper arm circumference } \\
(\mathrm{cm})\end{array}$ & 29.2 & 28.5 & 28.3 \\
\hline $\mathrm{BMI}\left(\mathrm{kg} / \mathrm{m}^{2}\right)$ & 27.82 & 27.37 & 27.49 \\
\hline
\end{tabular}


Table 3 The magnitude of agreement and the extent of misclassification on using different anthropometric measures instead of total skinfold thickness for measurement of body fat in pregnant women (90th percentile cut off). [N=3719]

\begin{tabular}{|c|c|c|c|c|c|}
\hline \multirow[t]{2}{*}{ Anthropometric measure } & \multirow{2}{*}{$\begin{array}{l}\text { Cut- } \\
\text { off }^{\#}\end{array}$} & \multicolumn{2}{|c|}{ Total skin fold thickness percentile } & \multirow{2}{*}{$\begin{array}{l}\text { Total } \\
\text { misclassification } \\
(\%)\end{array}$} & \multirow{2}{*}{$\begin{array}{l}\text { Kappa } \\
\text { coefficient (95\% } \\
\text { Cl) }\end{array}$} \\
\hline & & $<90$ th percentile & $>90$ th percentile & & \\
\hline \multirow[t]{2}{*}{ Body weight (kg) } & $<66.89$ & $2799(75.26)$ & $90(2.42)$ & \multirow[t]{2}{*}{17.32} & \multirow[t]{2}{*}{$0.38^{*}(0.34-0.41)$} \\
\hline & $\geq 66.89$ & $554(14.90)$ & $276(7.42)$ & & \\
\hline \multirow[t]{2}{*}{ Head circumference (cm) } & $<53.39$ & $2304(61.95)$ & $158(4.25)$ & \multirow[t]{2}{*}{32.46} & \multirow[t]{2}{*}{$0.12^{* *}(0.1-0.15)$} \\
\hline & $\geq 53.39$ & $1049(28.21)$ & $208(5.59)$ & & \\
\hline \multirow[t]{2}{*}{ Mid-upper Arm Circumference (cm) } & $<29.20$ & $2885(77.60)$ & $90(2.42)$ & \multirow[t]{2}{*}{15.01} & \multirow[t]{2}{*}{$0.42^{* * *}(0.38-0.46$} \\
\hline & $\geq 29.20$ & 468 (12.59) & $275(7.40)$ & & \\
\hline \multirow[t]{2}{*}{$\mathrm{BMI}\left(\mathrm{kg} / \mathrm{m}^{2}\right)$} & $<27.82$ & $2746(73.84)$ & $81(2.18)$ & \multirow[t]{2}{*}{18.5} & \multirow[t]{2}{*}{$0.36^{*}(0.33-0.40)$} \\
\hline & $\geq 27.82$ & $607(16.32)$ & $285(7.66)$ & & \\
\hline
\end{tabular}

\#Cut off corresponding to 90th percentile of total skinfold thickness

*Fair agreement; **Slight agreement; ${ }^{* * *}$ Moderate agreement [Landis \& Koch (1977)]
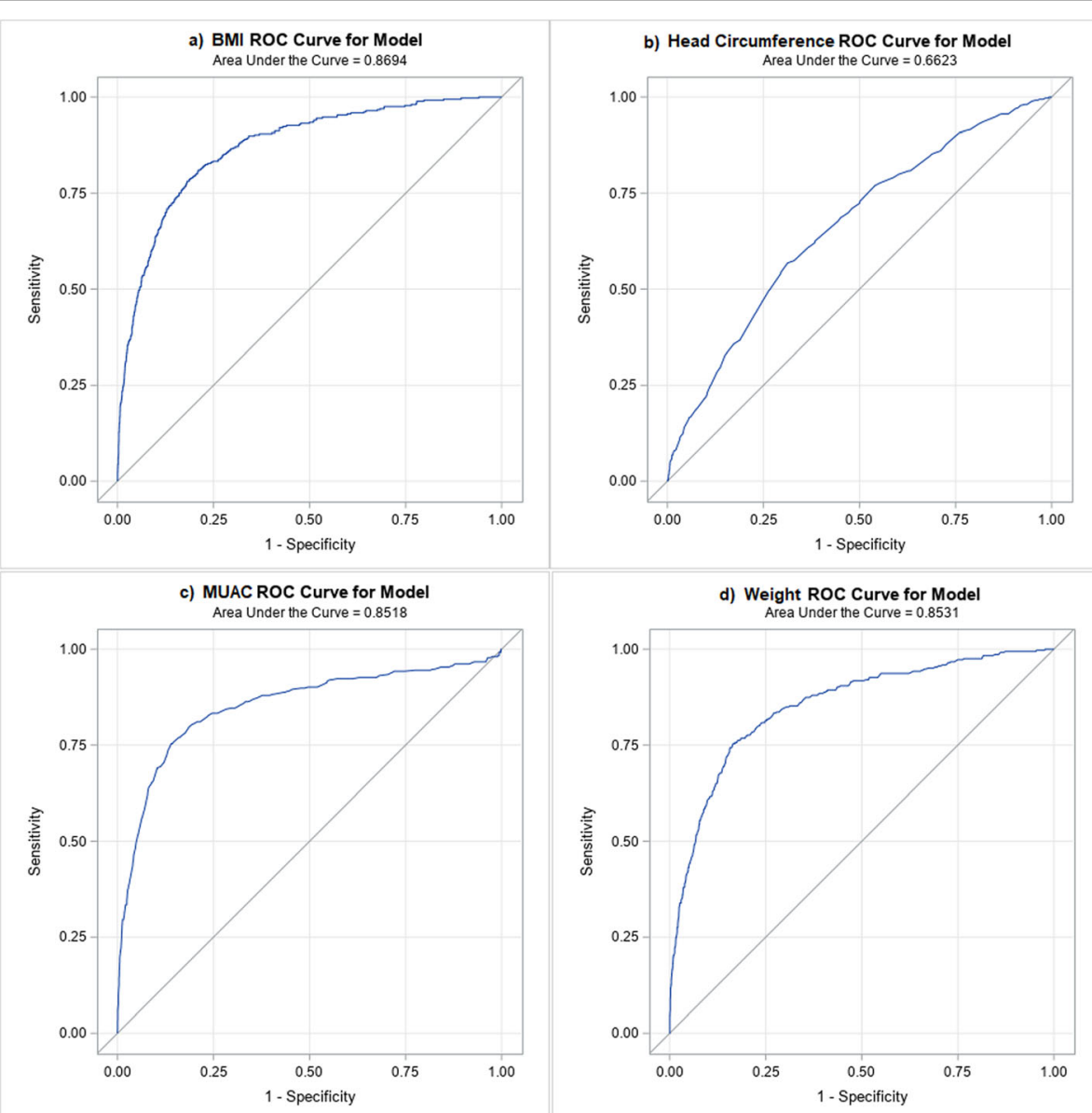

Fig. 1 Receiver operating characteristics (ROC) curves of maternal: (A) body mass index (BMI), (B) head circumference, (C) MUAC, and (D) body weight 
Table 4 Cut-offs for different anthropometric measures that correspond to total skinfold thickness cut-off (85th percentile) for children at birth - determined by different methods of ROC curve analysis. [ $N=2432]$

\begin{tabular}{|c|c|c|c|}
\hline \multirow[t]{2}{*}{ Anthropometric measure } & \multicolumn{3}{|c|}{ Cut-off corresponding to 85th percentile of total skinfold thickness from different methods } \\
\hline & $\begin{array}{l}\text { Youden's J } \\
\text { statistic }^{* *}\end{array}$ & $\begin{array}{l}\text { Minimized distance to }(0,1) \text { point in the ROC } \\
\text { curve }\end{array}$ & $\begin{array}{l}\text { Sensitivity-specificity } \\
\text { equality }\end{array}$ \\
\hline Bodyweight (kg) & 3.45 & 3.40 & 3.26 \\
\hline Head circumference $(\mathrm{Cm})$ & 35.00 & 34.70 & 34.60 \\
\hline Chest circumference $(\mathrm{Cm})$ & 33.70 & 33.70 & 33.40 \\
\hline Waist circumference $(\mathrm{Cm})$ & 31.70 & 32.40 & 32.40 \\
\hline Hip circumference $(\mathrm{Cm})$ & 30.30 & 30.30 & 30.50 \\
\hline $\begin{array}{l}\text { Mid-upper arm circumference } \\
(\mathrm{Cm})\end{array}$ & 10.30 & 10.30 & 10.30 \\
\hline $\mathrm{BMI}\left(\mathrm{kg} / \mathrm{m}^{2}\right)$ & 13.22 & 12.87 & 12.88 \\
\hline
\end{tabular}

*Sum of Biceps, Triceps and Sub-scapular skinfold thickness

** In case of discrepancy between cut-offs determined by different methods, the cut-off obtained via Youden's $J$ statistic was considered as standard

[40]. The available evidence supports our finding that intrauterine growth is best assessed by weight at birth [41, 42]. Similar findings were also found in other LMICs [36, 43].

In India, measuring MUAC in pregnancy and birth weight to assess obesity can help plan and prevent potential adverse outcomes. We recently showed that maternal obesity is an independent risk factor for neonatal adiposity [44]. Total skinfold measurement, the preferred method for assessing obesity, is often impeded by the dearth of trained staff, time, and costly equipment. In comparison, MUAC and birth weight measurements can be incorporated relatively easily in antenatal care services for immediate use in all hospitals. The weighing scales are available in all labour rooms, including rural health centres. Therefore, the measurement of birth weight can be done immediately after birth. This can be further validated in other geographies and settings (such as private hospitals) to arrive at a national consensus for cut-off so that appropriate obesity control measures can be taken in early childhood to prevent the deleterious health consequences in their adult life. Both the

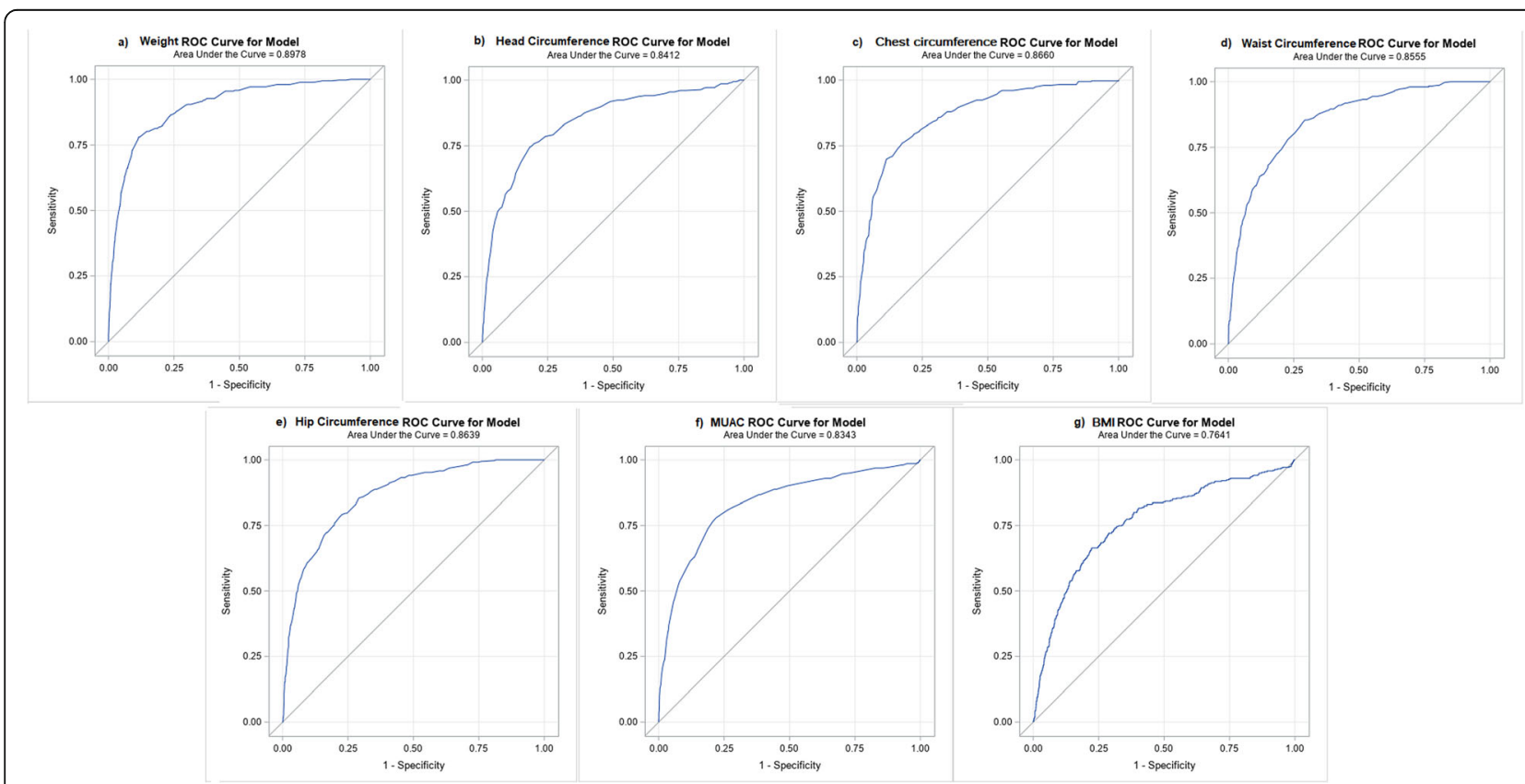

Fig. 2 Receiver operating characteristics (ROC) curves of infant anthropometric markers: (A) birthweight, (B) head circumference, (C) chest circumference, (D) waist circumference, (E) hip circumference, (F) MUAC, (G) BMI 
Table 5 The magnitude of agreement and the extent of misclassification on using different anthropometric measures instead of total skinfold thickness for measurement of body fat among children at birth (85th percentile cut-off). [N=2432]

\begin{tabular}{|c|c|c|c|c|c|}
\hline \multirow[t]{2}{*}{ Anthropometric measure } & \multirow{2}{*}{$\begin{array}{l}\text { Cut- } \\
\text { off }^{\#}\end{array}$} & \multicolumn{2}{|c|}{ Total skin fold thickness percentile } & \multirow{2}{*}{$\begin{array}{l}\text { Total } \\
\text { misclassification } \\
\text { (\%) }\end{array}$} & \multirow{2}{*}{$\begin{array}{l}\text { Kappa } \\
\text { coefficient } \\
(95 \% \mathrm{Cl})\end{array}$} \\
\hline & & $\leq 85$ th percentile & $>$ 85th percentile & & \\
\hline \multirow[t]{2}{*}{ Birth weight $(\mathrm{kg})[\mathrm{N}=2432]$} & $<3.45$ & $1839(75.62)$ & $78(3.21)$ & \multirow[t]{2}{*}{13.00} & \multirow{2}{*}{$\begin{array}{l}0.57^{*} \\
(0.52-0.60)\end{array}$} \\
\hline & $\geq 3.45$ & $238(9.79)$ & $277(11.39)$ & & \\
\hline \multirow[t]{2}{*}{ Head circumference $(\mathrm{cm})[N=2432]$} & $<35.00$ & $1699(69.86)$ & $90(3.70)$ & \multirow[t]{2}{*}{19.24} & \multirow{2}{*}{$\begin{array}{l}0.42^{*} \\
(0.38-0.46)\end{array}$} \\
\hline & $\geq 35.00$ & $378(15.54)$ & $265(10.90)$ & & \\
\hline \multirow[t]{2}{*}{ Chest circumference $(\mathrm{cm})[N=2432]$} & $<33.70$ & $1718(70.64)$ & $85(3.50)$ & \multirow[t]{2}{*}{18.26} & \multirow{2}{*}{$\begin{array}{l}0.45^{*} \\
(0.40-0.49)\end{array}$} \\
\hline & $\geq 33.70$ & $359(14.76)$ & $270(11.10)$ & & \\
\hline \multirow[t]{2}{*}{ Waist circumference (cm) } & $<31.70$ & $1469(60.40)$ & $52(2.14)$ & \multirow[t]{2}{*}{27.14} & \multirow{2}{*}{$\begin{array}{l}0.34^{* *} \\
(0.31-0.37)\end{array}$} \\
\hline & $\geq 31.70$ & $608(25.00)$ & $303(12.46)$ & & \\
\hline \multirow[t]{2}{*}{ Hip circumference $(\mathrm{cm})$} & $<30.30$ & $1609(66.16)$ & $74(3.04)$ & \multirow[t]{2}{*}{22.28} & \multirow{2}{*}{$\begin{array}{l}0.39^{* *} \\
(0.35-0.43)\end{array}$} \\
\hline & $\geq 30.30$ & $468(19.24)$ & $281(79.15)$ & & \\
\hline \multirow[t]{2}{*}{ Mid Upper Arm Circumference $(\mathrm{Cm})$} & $<10.30$ & $1621(66.65)$ & $78(3.21)$ & \multirow[t]{2}{*}{21.96} & \multirow{2}{*}{$\begin{array}{l}0.39^{* *} \\
(0.35-0.43)\end{array}$} \\
\hline & $\geq 10.30$ & $456(18.75)$ & $277(11.39)$ & & \\
\hline \multirow[t]{2}{*}{ BMI (kg/m2) } & $<13.22$ & $1609(66.19)$ & $119(4.90)$ & \multirow[t]{2}{*}{24.11} & \multirow{2}{*}{$\begin{array}{l}0.31^{* *} \\
(0.27-0.35)\end{array}$} \\
\hline & $\geq 13.22$ & $467(19.21)$ & 236 (9.71) & & \\
\hline
\end{tabular}

anthropometric markers as alternatives for skinfold thickness in our study demonstrated the feasibility for use in public facilities due to the usability and costs involved.

Firstly, some of the limitations are the need to ensure adequate training for the healthcare staff for MUAC measurement. However, MUAC is less resource and skill-intensive compared to skinfold thickness assessment. Secondly, there could be misclassification resulting from using a substitute measure for total skinfold thickness in obesity measurement; a certain proportion of the population may wrongly get classified obese (or vice versa) when they are not so. Further validation studies in India can establish the reliability and validity to steer policy-level actions to prioritise screening obesity in pregnancy. The third limitation is that this study mostly represents the source population comprising low-middle-income women who attend public facilities in Bengaluru. This needs to be validated in an even larger population to prove its wider applicability. However, we were able to capture the measurements among a large sample size of mother-child dyads and thus have shown the use at public facilities for urban populations that can be applied across the country.

\section{Conclusion}

Mid-upper arm circumference and birth weight can be used as markers of skinfold thickness, reflecting total body fat in pregnant women and infants, respectively. These two anthropometric measurements could substitute for skinfold thickness in low- and middleincome urban India settings. Our results suggest that the MUAC and birth weight be used in pregnant women and infants, respectively, as markers for effective screening tools for detection of obesity in Indian states and other similar settings. The simple technique and low costs associated with measurements can enable the implementation by frontline health workers including in rural areas.

\section{Supplementary information}

The online version contains supplementary material available at https://doi. org/10.1186/s12884-021-03915-1.

\section{Additional file 1 \\ Additional file 2 \\ Additional file 3 \\ Additional file 4}

\section{Acknowledgements}

We sincerely thank the Department of Health and Family Welfare, the Government of Karnataka (DoHFW, GoK) and the Bruhat Bengaluru Mahanagara Palike (BBMP) for permitting us to conduct the study and providing constant support. We thank hospitals under DoHFW, GoK, Superintendents, Medical Officers, Doctors, and all the department support staff for the support in an ongoing study. We thank Dr. Sumathi

Swaminathan and her team at St John's Research Institute for training the Research Assistants in anthropometry measurement. Our sincere thanks to the Welcome Trust, DBT India Alliance, for the support with funding and guidance. Our sincere thanks to Dr. Suresh Shapeti and Mr. T.S. Ramesh for facilitating the administrative support and coordination. We thank all the research team members of MAASTHI for their support in carrying out research activities in the field. We thank all participants for their effort to enroll and continuous participation in the ongoing cohort. 


\section{Authors' contributions}

GRB and AD contributed to conception and design. AD analysed the data. EL, DR, and DJ drafted the manuscript. PT, SK, SBN, and GVS contributed to interpretation and to critically revising the manuscript. All authors gave final approval and agree to be accountable for all aspects ensuring integrity and accuracy.

\section{Funding}

This work was supported by the Wellcome Trust/DBT India Alliance Fellowship [Grant No. IA/CPHI/14/1/501499] awarded to Giridhara R. Babu. The funding agency had no role in the design and conduct of the study; collection, management, analysis, and interpretation of the data; preparation, review, or approval of the manuscript; or decision to submit the manuscript for publication.

\section{Availability of data and materials}

The data that support the findings of this study are not publicly available, but applications for data access can be submitted to the corresponding author on reasonable request.

\section{Declarations}

\section{Ethics approval and consent to participate}

The study was reviewed and approved by the Institutional ethics committee (IEC) of the Indian Institute of Public Health - Bengaluru campus vide IEC no. IIPHHB/TRCIEC/091/2015 dated 13th July 2015 and IEC no. IIPHHB/TRCIEC/ 121/2017 dated 24th July 2017. The study was conducted in accordance with the Declaration of Helsinki.

\section{Consent for publication}

Written informed consent before participation in the study was obtained from all voluntary willing participants for participation, follow-ups, and permission to publish anonymous data in any report and journal after delivery. Infants were measured for anthropometry after obtaining consent from the participant in the presence of a family member.

\section{Competing interest}

The authors declare that they have no competing interests.

\begin{abstract}
Author details
'Indian Institute of Public Health-Bengaluru, Public Health Foundation of India (PHFI), Bengaluru, India. ${ }^{2}$ Wellcome Trust-DBT India Alliance Intermediate Research Fellow in Public Health, Hyderabad, India. ${ }^{3}$ Bihar Technical Support Program, CARE India, Patna, India. ${ }^{4}$ Nutrition Division, St Johns Research Institute, Bengaluru, India. ${ }^{5}$ Asian Development Bank (ADB) NCR - National Capital Region, Manila, Philippines. ${ }^{6}$ Department of Health, Behavior and Society, Johns Hopkins Bloomberg School of Public Health, Baltimore, MD, USA. IIndian Institute of Public Health-Hyderabad, Public Health Foundation of India (PHFI), Hyderabad, India. ${ }^{8}$ Public Health Eye Care \& Disability, London School of Hygiene \& Tropical Medicine, London, United Kingdom.
\end{abstract}

\section{Received: 23 January 2021 Accepted: 26 May 2021}

Published online: 06 July 2021

\section{References}

1. Qiao Y, Ma J, Wang Y, Li W, Katzmarzyk PT, Chaput J-P, et al. Birth weight and childhood obesity: a 12-country study. International journal of obesity supplements. 2015;5(2):S74-S9.

2. Subramanyam V, Rafi M. Prevalence of overweight and obesity in affluent adolescent girls in Chennai in 1981 and 1998. Indian pediatrics. 2003;40(4): 332-6.

3. Jain S, Pant B, Chopra H, Tiwari R. Obesity among adolescents of affluent public schools in Meerut. Indian journal of public health. 2010;54(3):158

4. Kaur S, Kapil U, Singh P. Pattern of chronic diseases amongst adolescent obese children in developing countries. Current science. 2005:1052-6.

5. Laxmaiah A, Nagalla B, Vijayaraghavan K, Nair M. Factors affecting the prevalence of overweight among 12-to 17-year-old urban adolescents in Hyderabad, India. Obesity. 2007;15(6):1384-90.

6. Chen $C, X u X$, Yan Y. Estimated global overweight and obesity burden in pregnant women based on panel data model. 2018.
7. Swaminathan S, Hemalatha R, Pandey A, Kassebaum NJ, Laxmaiah A, Longvah T, et al. The burden of child and maternal malnutrition and trends in its indicators in the states of India: the Global Burden of Disease Study 1990-2017. The Lancet Child \& Adolescent Health. 2019;3(12):855-70.

8. Chopra M, Kaur N, Singh KD, Maria Jacob C, Divakar H, Babu GR, et al. Population estimates, consequences, and risk factors of obesity among pregnant and postpartum women in India: Results from a national survey and policy recommendations. International Journal of Gynecology \& Obstetrics. 2020;151:57-67.

9. Bishwajit $\mathrm{G}$, Yaya S. Overweight and obesity among under-five children in South Asia. Child and Adolescent Obesity. 2020;3(1):105-21.

10. International laM, editor Ministry of Health and Family Welfare Fact Sheets Key Indicators 22 States/UTs from Phase-12020.

11. Malik M, Khanna P, Verma R. The association of maternal risk factors to macrosomia in rural areas of Haryana, India: a community based study. International Journal Of Community Medicine And Public Health. 2018;5(9): 3842-6.

12. Council NR. Weight gain during pregnancy: reexamining the guidelines: National Academies Press; 2010.

13. Sangachin MG, Cavuoto LA, Wang Y. Use of various obesity measurement and classification methods in occupational safety and health research: a systematic review of the literature. BMC obesity. 2018;5(1):28.

14. Craig E, Bland R, Ndirangu J, Reilly J. Use of mid-upper arm circumference for determining overweight and overfatness in children and adolescents. Archives of disease in childhood. 2014;99(8):763-6.

15. Group WMGRS, de Onis M. Reliability of anthropometric measurements in the WHO Multicentre Growth Reference Study. Acta Paediatrica. 2006;95:3846.

16. Shypailo RJ, Butte NF, Ellis KJ. DXA: can it be used as a criterion reference for body fat measurements in children? Obesity. 2008;16(2):457-62.

17. Barbour LA, Hernandez TL, Reynolds RM, Reece MS, Chartier-Logan C, Anderson MK, et al. Striking differences in estimates of infant adiposity by new and old DXA software, PEAPOD and skin-folds at 2 weeks and 1 year of life. Pediatric obesity. 2016;11(4):264-71.

18. Shafer KJ, Siders WA, Johnson LK, Lukaski HC. Validity of segmental multiplefrequency bioelectrical impedance analysis to estimate body composition of adults across a range of body mass indexes. Nutrition. 2009;25(1):25-32.

19. Goran MI. Measurement issues related to studies of childhood obesity: assessment of body composition, body fat distribution, physical activity, and food intake. Pediatrics. 1998;101(Supplement 2):505-18.

20. Babu GR, Murthy GVS, Deepa R, Kumar HK, Karthik M. Maternal antecedents of adiposity and studying the transgenerational role of hyperglycemia and insulin (MAASTHI): a prospective cohort study Protocol of birth cohort at Bangalore, India. BMC pregnancy and childbirth. 2016:1-9.

21. Hediger ML, Luke B, van de Ven C, Nugent C. Midupper arm circumference (MUAC) changes in late pregnancy predict fetal growth in twins. Twin research and human genetics. 2005;8(3):267-70.

22. Metzger BE, Lowe LP, Dyer AR, Trimble ER, Sheridan B, Hod M, et al. Hyperglycemia and Adverse Pregnancy Outcome (HAPO) Study: associations with neonatal anthropometrics. Diabetes. 2008.

23. Youden WJ. Index for rating diagnostic tests. Cancer. 1950;3(1):32-5.

24. Pandey M, Jain A. ROC Curve: Making way for correct diagnosis2016 October 25, 2017; SP11 - PharmaSUG 2016. Available from: https://www.pha rmasug.org/proceedings/2016/SP/PharmaSUG-2016-SP11.pdf.

25. Reiser B. Measuring the effectiveness of diagnostic markers in the presence of measurement error through the use of ROC curves. Statistics in medicine. 2000;19(16):2115-29.

26. Faraggi $\mathrm{D}$. The effect of random measurement error on receiver operating characteristic (ROC) curves. Statistics in medicine. 2000;19(1):61-70.

27. Das A, Saimala G, Reddy N, Mishra P, Giri R, Kumar A, et al. Mid-upper arm circumference as a substitute of the body mass index for assessment of nutritional status among adult and adolescent females: learning from an impoverished Indian state. Public health. 2020;179:68-75.

28. Moll U, Olsson H, Landin-Olsson M. Impact of pregestational weight and weight gain during pregnancy on long-term risk for diseases. PloS one. 2017;12(1).

29. NHSRC. Household Healthcare Utilization \& Expenditure in India: State Fact Sheets. In: Ministry of Health and Family Welfare Gol, editor.

30. Aung TZ, Oo WM, Khaing W, Lwin N, Dar HT. Late initiation of antenatal care and its determinants: a hospital based cross-sectional study. Int J Community Med Public Health. 2017;3(4):900-5. 
31. Jayawardena R, Punchihewa P, Chinthanie S, Lokunarangoda N, Pathirana AK. The use of mid upper arm circumference and skinfold thickness to assess underweight and obesity among cardiac patients. Sri Lanka Journal of Diabetes Endocrinology and Metabolism. 2017;7(2).

32. Okereke C, Anyaehie U, Dim C, lyare E, Nwagha U. Evaluation of some anthropometric indices for the diagnosis of obesity in pregnancy in Nigeria: a cross-sectional study. African health sciences. 2013;13(4):1034-40.

33. Tang AM, Dong K, Deitchler M, Chung M, Maalouf-Manasseh Z, Tumilowicz A, et al. Use of cutoffs for mid-upper arm circumference (MUAC) as an indicator or predictor of nutritional and health-related outcomes in adolescents and adults: a systematic review. 2013.

34. Fakier A, Petro G, Fawcus S. Mid-upper arm circumference: a surrogate for body mass index in pregnant women. South African Medical Journal. 2017; 107(7):606-10.

35. López LB, Calvo EB, Poy MS, del Valle Balmaceda Y, Cámera K. Changes in skinfolds and mid-upper arm circumference during pregnancy in Argentine women. Maternal \& child nutrition. 2011;7(3):253-62.

36. Tikellis G, Ponsonby A, Wells J, Pezic A, Cochrane J, Dwyer T. Maternal and infant factors associated with neonatal adiposity: results from the Tasmanian Infant Health Survey (TIHS). International journal of obesity. 2012;36(4):496504.

37. Kuriyan R, Naqvi S, Bhat KG, Ghosh S, Rao S, Preston T, et al. The Thin But Fat Phenotype is Uncommon at Birth in Indian Babies. The Journal of Nutrition. 2019.

38. Yajnik CS, Fall CHD, Coyaji KJ, Hirve SS, Rao S, Barker DJP, et al. Neonatal anthropometry: the thin-fat Indian baby. The Pune Maternal Nutrition Study. International Journal of Obesity. 2003;27(2):173-80.

39. Muthayya S, Dwarkanath P, Thomas T, Vaz M, Mhaskar A, Mhaskar R, et al. Anthropometry and body composition of south Indian babies at birth. Public health nutrition. 2006;9(7):896-903.

40. Jain V, Kurpad A, Kumar B, Devi S, Sreenivas V, Paul V. Body composition of term healthy Indian newborns. European journal of clinical nutrition. 2016; 70(4):488-93.

41. Pereira-Freire JA, Lemos JO, de Sousa AF, Meneses CC, Rondó PHC. Association between weight at birth and body composition in childhood: a Brazilian cohort study. Early human development. 2015;91(8):445-9.

42. Chen L-W, Tint M-T, Fortier MV, Aris IM, Shek LP, Tan KH, et al. Which anthropometric measures best reflect neonatal adiposity? International Journal of Obesity. 2018:42(3):501-6.

43. Choukem S-P, Njim T, Atashili J, Hamilton-Shield JP, Mbu R. High birth weight in a suburban hospital in Cameroon: an analysis of the clinical cutoff, prevalence, predictors and adverse outcomes. BMJ open. 2016;6(6): e011517.

44. Babu GR, Deepa R, Lewis MG, Lobo E, Krishnan A, Ana Y, et al. Do Gestational Obesity and Gestational Diabetes Have an Independent Effect on Neonatal Adiposity? Results of Mediation Analysis from a Cohort Study in South India. Clinical Epidemiology. 2019;Volume 11:1067-80.

\section{Publisher's Note}

Springer Nature remains neutral with regard to jurisdictional claims in published maps and institutional affiliations.

\section{Ready to submit your research? Choose BMC and benefit from:}

- fast, convenient online submission

- thorough peer review by experienced researchers in your field

- rapid publication on acceptance

- support for research data, including large and complex data types

- gold Open Access which fosters wider collaboration and increased citations

- maximum visibility for your research: over $100 \mathrm{M}$ website views per year

At $\mathrm{BMC}$, research is always in progress.

Learn more biomedcentral.com/submissions 